\title{
Patient satisfaction and oral health-related quality of life 10 years after implant placement
}

\author{
Yan Wang ${ }^{1}$, Daniel Bäumer ${ }^{1}$, Ann-Kathrin Ozga ${ }^{2,3}$, Gerd Körner ${ }^{4}$ and Amelie Bäumer ${ }^{4,5^{*}}$ (D)
}

\begin{abstract}
Background: Implant survival and implant success (freedom of biologic complications) are important factors in assessing the success of implant therapy. However, these factors are not the only determinants. Patients' satisfaction also plays a very important role in daily practice. Therefore, the aim of this study was to assess patients' satisfaction regarding function (phonetics, chewing comfort, stability, cleanability) and aesthetics in patients treated with XiVE and Frialite implants in a private periodontal practice ten years after implant placement. Furthermore, oral healthrelated quality of life (OHRQoL) was evaluated.
\end{abstract}

Methods: Patient-reported outcome measures (PROMs) regarding overall satisfaction, phonetics, chewing comfort, stability, cleanability, and aesthetics were examined on a Visual Analog Scale (VAS) 10 years \pm 6 months after implant placement in a cross-sectional survey. OHRQoL and psychological impact were assessed via the Oral Health Impact Profile (OHIP) and Psychosocial Impact of Dental Aesthetics Questionnaire (PIDAQ). Potential influence of patient-related factors (age, gender, smoking, peri-implantitis, implant position, type of restoration) on VAS, OHRQoL and PIDAQ were investigated using regression analyses.

Results: High satisfaction with implant-supported restorations was seen in all 95 patients ten years after implant placement. Mean VAS-score for general satisfaction with implant-supported restoration was 93.0\% (SD \pm 9.4, median: 96.3\%, range 50.0-100\%). Mean OHIP score was 11.3 (SD \pm 10.8 , median: 9.0, range 0-45), mean PIDAQ score 20.5 ( $S D \pm 11.37$, median: 17.0, range 0-52). A slight tendency that presence of a moderate/severe peri-implantitis lowers satisfaction could be detected (overall satisfaction: ordinal, $p=0.012$, VAS, $p=0.026$ ). Also, the factors age, implant position and type of restoration might have an impact on patient's satisfaction.

Conclusions: Patients restored with mostly fixed implant-supported restorations showed a very high patient satisfaction regarding function and aesthetics 10-year after implant placement. The presence of a moderate/severe peri-implantitis showed a slight tendency for influencing patient satisfaction. Due to the cross-sectional design results have to be interpreted with care.

Keywords: Implants, Patient satisfaction, Aesthetics, Quality of life, OHIP, PIDAQ

\section{Background}

Implant-supported restorations have become standard for the therapy of lost or missing teeth. Survival rates of implants are high $[1,2]$. However, the time an

*Correspondence: ab@paroplant.com; amelie.baeumer-koenig@med. uni-heidelberg.de

${ }^{4}$ Private Practice, Niedernstrasse 16, 33602 Bielefeld, Germany

Full list of author information is available at the end of the article implant remains in situ is not the only factor determining the success of implant therapy. Much more relevant for implant success is, whether the hard and soft tissues around implants are free of inflammation. Other important aspects are functional and aesthetic outcomes of the implant-supported restorations. Altogether, these criteria are essential for the aspired improvement in life quality. Patients experience the improvement of life quality 
individually. This phenomenon is referred to as patients satisfaction [3-5].

Health is one of the important dimensions regarding quality of life (c). Even though oral diseases with local symptoms, such as pain or tooth loss, are generally not life threatening, they can greatly affect the health-related quality of life (called oral health-related quality of life, OHRQoL). The extent of the impairment is influenced by position and distribution of the affected or lost teeth [6]. Patients ask for solutions in order to compensate such kind of impairment and to re-establish their quality of life. Since the introduction of dental implants, one of the most common impairments-missing teeth-can be treated very effectively. Thus, the improvement in quality of life is a major treatment goal for implant-supported restorations and the patient satisfaction should be regarded as a central feature for treatment quality and success of therapy [7].

Patients' self-awareness reflects their need for therapy; patient-reported outcome measures (PROMs) are able to show whether a treatment was able to improve their quality of life, for example by use of an implant-supported restoration. Additionally, PROMs can be used to evaluate the patients' understanding of the performed treatment; a sufficiently good understanding can positively influence the commitment of the patient. Also, PROMs can be helpful for communication between decisionmakers within the health care system, as therapies such as implant-supported restorations can be mediated in a tangible language that is easier to understand. In addition, PROMs are also potentially useful for the economic evaluation of various treatment methods [8].

Oral Health Impacted Profile (OHIP) is an internationally recognized instrument for evaluating the oral health-related quality of life [9-14]. For the purpose of an intercultural and international comparability of this psychometric instrument, this questionnaire was translated in 2002 with cultural adaptation into German. Four questions were added, which were specifically regarded as meaningful to the German population [15]. The culturespecific German version of the questionnaire has also proven its validity and sensitivity both in cross-sectional and longitudinal studies [16-18].

The Psychosocial Impact of Dental Aesthetics Questionnaire (PIDAQ) was developed in 2006 in order to investigate the effects of aesthetics on quality of life [19]. It is a well-validated psycho-social method for assessing the need for treatment as well as the treatment outcomes [19-23].

Since patients are no longer focused on the healing process with possible pain, swelling or bleeding, longterm follow-up studies over five years or more involving patient satisfaction survey provide reasonable information on real treatment benefit [4]. Although several long-term data regarding survival and success rates over periods of at least ten years are available for different implant systems [24-27], long-term results on patient satisfaction and individual improvement in quality of life are still rare [8]. Especially for the implant system XiVE and Frialite (Fa. Dentsply Sirona Implants, Mannheim, Germany), only one study concerning patient-reported outcomes is available with an observation period of 7.5 years [28].

Therefore, the aim of this study was to collect data of patient-reported outcomes in patients with XiVE and Frialite implants in a private periodontal practice 10 years after implant placement. Furthermore, factors potentially influencing patient satisfaction are investigated.

\section{Methods}

The study was performed in accordance with the Declaration of Helsinki 1975, as revised in 2013, and was approved by the Institutional Review Board for Human Studies of the Medical Faculty of Heidelberg University (Application\# S-210/2013). All patients were informed about possible risks and benefits as well as the procedures of the study and all gave written informed consent.

\section{Study population}

As described in a previous paper on implant survival and success [29] all invited patients were treated in a private periodontal practice by implant placement of at least one XIVE or Frialite implant (Fa. Dentsply Sirona Implants, Mannheim, Germany). All patients were incorporated in an individual hygiene program prior to implant placement. If a periodontal disease was diagnosed, patients additionally received an active periodontal therapy (APT) prior to implant surgery. After implant placement all patients were invited in a recall program. 10 years \pm 6 months after implant placement a re-examination was conducted.

All patients had to fulfill the following criteria:

- Available panoramic radiograph at implant placement (+3 months) and/or time of inserting the implant-supported prostheses (orthopantomogramm or x-ray)

- Available attachment level or panoramic radiograph/ complete $\mathrm{x}$-ray status to classify patient's periodontal diagnosis at baseline

- Age $\geq 18$ years at re-examination

- Non-pregnant or breastfeeding

- Partially edentulous dentition

- Completed questionnaires 


\section{Clinical examination}

After complete clinical re-examination performed by one independent examiner $(\mathrm{AB})$ patients were asked to fulfill three questionnaires (clinical examination is described in detail in Bäumer et al. [29]):

\section{Patients satisfaction}

Patients answered six questions regarding their satisfaction on (1) general state, (2) phonetics, (3) chewing comfort, (4) stability, (5) cleanability, and (6) aesthetics using a four-grade categorizing scale: (a) "yes, very satisfied", (b) "yes, mostly satisfied", (c) "less satisfied", (d) "not at all satisfied".

In addition, patients were asked to mark for each question the respective Visual Analog Scale (VAS) [30] which is a $100 \mathrm{~mm}$ straight horizontal line with the left end indicating "not at all satisfied" and the right end "very satisfied". The satisfaction value was determined by the distance from the left end of the scale to the mark in millimeters and expressed as percentage $(10 \mathrm{~mm}$ corresponds to $10 \%, 20 \mathrm{~mm} 20 \%$, etc.)

\section{Oral health impact profile (OHIP)}

Oral health-related quality of life (OHRQoL) was measured by using the German version of Oral Health Impact Profile (OHIP, 49 items) [13, 15]. For international comparability, the four German-specific questions were excluded. Patients were asked about the frequencies of complains during the last month.

A total of 49 OHRQoL-factors were rated on a scale of $0-4 \quad(0=$ "never", $1=$ "rarely", $2=$ "occasionally", $3=$ "often", $4=$ "very often"). There was no weighting of each single factor $[15,31]$. The OHIP summary score was calculated as the sum of the 49 sub-scores (range 0-212) and characterized impairment. A higher OHIP score indicates a poorer OHRQoL. If more than five questions in total, two questions in a subgroup, or one of the three questions on problems specific to patients with prostheses were not answered, the patient was excluded. For all other cases, a statistical estimate gained via multiple imputation was used to supplement missing responses.

\section{Psychosocial impact of dental aesthetics questionnaire (PIDAQ)}

Influence of aesthetic perception of teeth in daily life was evaluated by consents to 23 statements. The consents to aesthetic-negative statements were rated on a scale of $0-4(0=$ "not at all", $1=$ "a little", $2=$ "somewhat", $3=$ "strongly" or $4=$ "very strongly"). Since the subgroup "dental self-confidence" consisted of aesthetic-positive statements, the scales were rated reversed. Thus, a total score of 0 would represent an absolute satisfaction of aesthetics and a maximum total score of 115 would represent absolute dissatisfaction.

\section{Statistical analysis}

Data was imported by two independent examiners (YW, DB) into the software "Microsoft ${ }^{\circledR}$ Excel for Mac 2011" (Microsoft Corporation, Redmond). For statistical analysis the statistics software R 3.2.2 (R Foundation for Statistical Computing, Vienna, Austria, www.r-project.com) was used. A descriptive analysis with mean, standard deviation, median, minimum, and maximum for continuous data was conducted. For categorial data percentages are given.

Statistical significance of potentially influencing factors (age, sex, smoking, peri-implantitis, implant position, type of restoration) on ordinal measurements of patient satisfaction was determined by ordinal or in one case logistic regression analysis. For continuous measurement variables (VAS, OHIP or PIDAQ) linear regression analyses were used. Estimates (odds ratio, mean difference) are given with corresponding 95\% confidence interval and $p$ value. If more than five OHIP score questions in total, two questions in an OHIP score subgroup, or one of the three questions on problems specific to patients with prostheses were not answered, the patient was excluded. For all other cases, a statistical estimate gained via multiple imputation was used to supplement missing responses. Thereby, the mice function in the mice package in $\mathrm{R}$, which generates multivariate imputations by chained equations was used. Due to the descriptive nature of this study no adjustment for multiple testing was carried out and the significance level was set to be 0.05 .

\section{Results}

\section{Study population data}

103 out of 210 patients could be reexamined. In these analyses, 95 patients $(60.0 \%$ female) are incorporated. Reasons for exclusion of eight patients are given in Fig. 1.

At baseline 33 patients showed a mild/moderate chronic periodontitis (ChP), 20 a severe ChP, 4 a localized aggressive periodontitis (AgP), and 11 a generalized AgP. All enrolled patients graduated at least from secondary school, $56.8 \%$ were also college/university graduates. At time of re-examination $9.5 \%$ of the patients were smokers and $44.2 \%$ were former smokers.

Patients were aged 28-86 years (mean 63.4 years, $\mathrm{SD} \pm 10.4$ years). Follow-up time was 10 years \pm 6 month (mean 10.0 years, $\mathrm{SD} \pm 0.3$ years) after implant placement. The patients received one to nine implants (mean $2.5, \mathrm{SD} \pm 1.6)$. Only five patients (5.3\%) got implantsupported prostheses, while 90 (94.7\%) were restored with fixed single crowns or partial bridges. $40.0 \%$ of all 


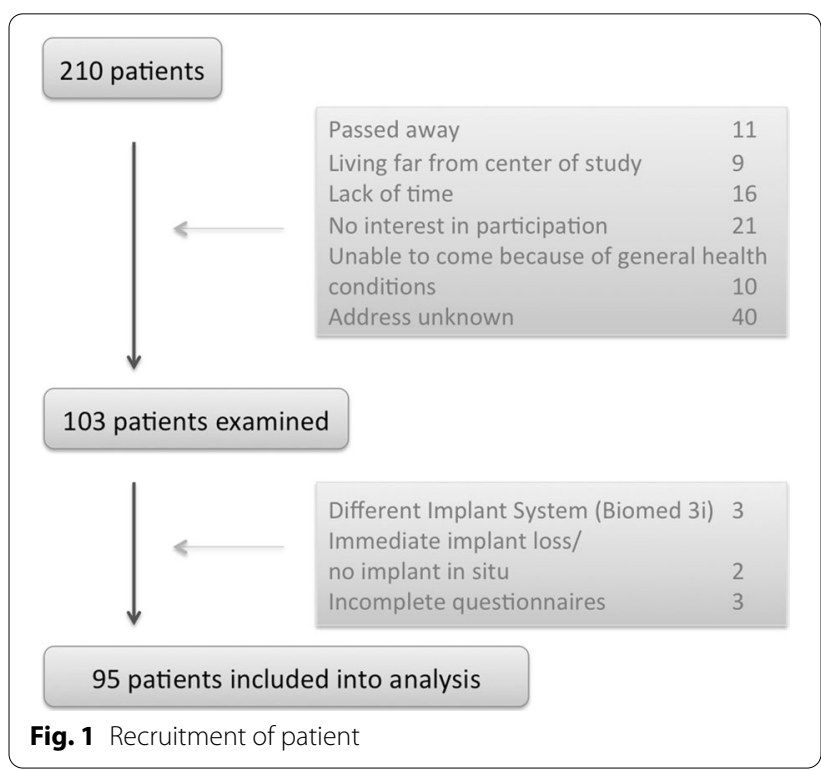

patients suffered from mild peri-implantitis and $16.8 \%$ from moderate/severe peri-implantitis (Table 1).

\section{Patient satisfaction (PROMs)}

Overall satisfaction. $87.4 \%$ of all patients were strongly satisfied with their implant therapy. Only $11.6 \%$ responded with "yes, mostly" satisfied. Mean VAS was 93.1\% (SD \pm 9.4 , median 96.3\%, range 50.0100\%) (Fig. 2a, b and Additional file 1).

Phonetics. $100 \%$ of the patients were strongly satisfied with their phonetics. Mean VAS was $96.7 \%$ ( $\mathrm{SD} \pm 5.8$, median $98.0 \%$, range $53.8-100 \%$ ).

Chewing comfort. $91.6 \%$ of patients were strongly satisfied with their chewing comfort, $8.4 \%$ of patients responded "yes, with slight restrictions". Mean VAS was 94.2\% ( $\mathrm{SD} \pm 8.6$, median was $97.3 \%$, range $47.0-100 \%$ ).

Stability. $87.4 \%$ of patients answered "yes, very", $11.6 \%$ with "yes, for the most part". Mean VAS was 94.1\% (SD \pm 8.3 , median 97.3\%, range 54.3-100\%).

Cleanability. $66.3 \%$ of the patients had no problems with the cleanability of their restoration. $31.6 \%$ of the patients had mostly no problems and one patient (1.1\%) perceived the cleanability to be inferior. Mean VAS was $90.0 \%$ ( $S D \pm 11.76$, median $96.3 \%$, range 52.3-100\%).

Aesthetics. $84.2 \%$ of the patients were very satisfied with the aesthetics of the implant-supported restoration, $12.6 \%$ responded to be mostly satisfied, and $1.1 \%$ of patients less satisfied with the aesthetics. Mean VAS was $93.3 \%(\mathrm{SD} \pm 11.37$, median $97.0 \%$, range $23.0-100.0 \%)$.
Table 1 Patient characteristics

\begin{tabular}{ll}
\hline Patient characteristics & Total $(\boldsymbol{n}=\mathbf{9 5})$ \\
\hline Sex (female) & $57(60 \%)$ \\
Age (years) & $63.4 \pm 10.3$ (range 28-86) \\
Follow-up time (years) & $10 \pm 0.3$ (range 9.5-10.7) \\
Smoking at reexamination & \\
Current smoker & $9(9.5 \%)$ \\
Former smoker & $42(44.2 \%)$ \\
Never smoker & $44(46.3 \%)$ \\
Educational status & \\
Secondary school graduates & $95(100.0 \%)$ \\
College/university graduates & $54(56.8 \%)$ \\
Position of implants & \\
Anteriors & $28(29.5 \%)$ \\
Premolars & $35(36.8 \%)$ \\
Molars & $32(33.7 \%)$ \\
Prosthetic treatment & \\
Implant supported single crown & $63(66.3 \%)$ \\
Implant supported fixed prosthesis & $27(28.4 \%)$ \\
Removable denture & $5(5.3 \%)$ \\
Number of implants & $2.5 \pm 1.6($ range $1-9)$ \\
Implant type & $84(88.4 \%)$ \\
XiVE & $11(11.6 \%)$ \\
Frialit & \\
Peri-implantitis at reexamination & $41(43.2 \%)$ \\
No peri-implantitis & $38(40.0 \%)$ \\
Mild peri-implantitis & $16(16.8 \%)$ \\
Moderate/severe peri-implantitis & \\
\hline Cronicperodontis, & \\
\hline
\end{tabular}

${ }^{\ddagger}$ Chronic periodontitis, ${ }^{\S}$ aggressive periodontitis

Patients who answered the questions with "very satisfied" did give higher VAS than patients that answer with "mostly satisfied" (Additional file 1: Fig. S1).

To summarize, these results indicate a profound patient satisfaction. This is also reflected by the fact that $98.9 \%$ of the patients would choose the treatment option of an implant-supported restoration again, if indicated. Only a single patient (1.1\%) would not.

\section{OHIP}

For four of the 95 patients, the OHIP scores could not be determined, because 5 or more questions of the questionnaire were not answered. The answers for all 49 questions of the 91 evaluable questionnaires are summarized in Table 2.

Mean OHIP score was 11.3 ( $\mathrm{SD} \pm 10.8$, median 9, range $0-45$, 1st quantil 3, 3rd quantil 16.5). The median of 9.0 signifies that half of all patients rank on the top $5 \%$ of the OHIP scale. 11 patients (11.6\%) experienced no impairment of OHRQoL in the last month, thus exhibit the best possible OHIP score of zero. In sum, this indicates once 
a

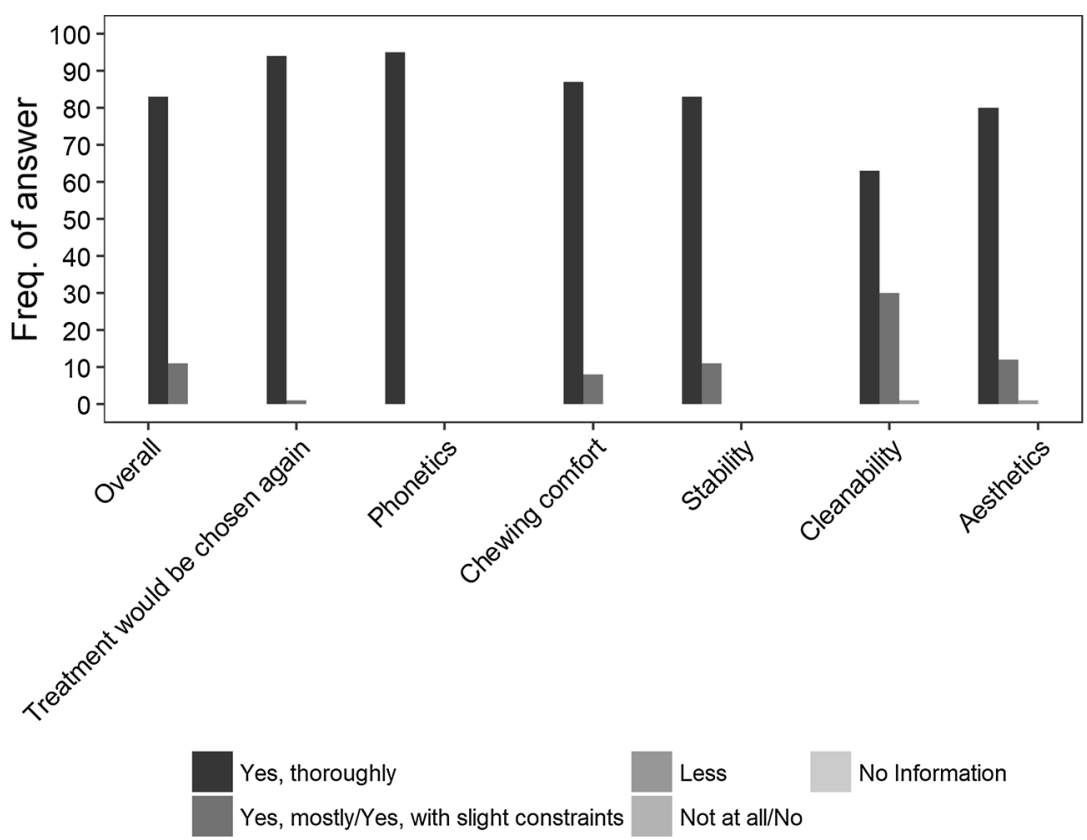

b

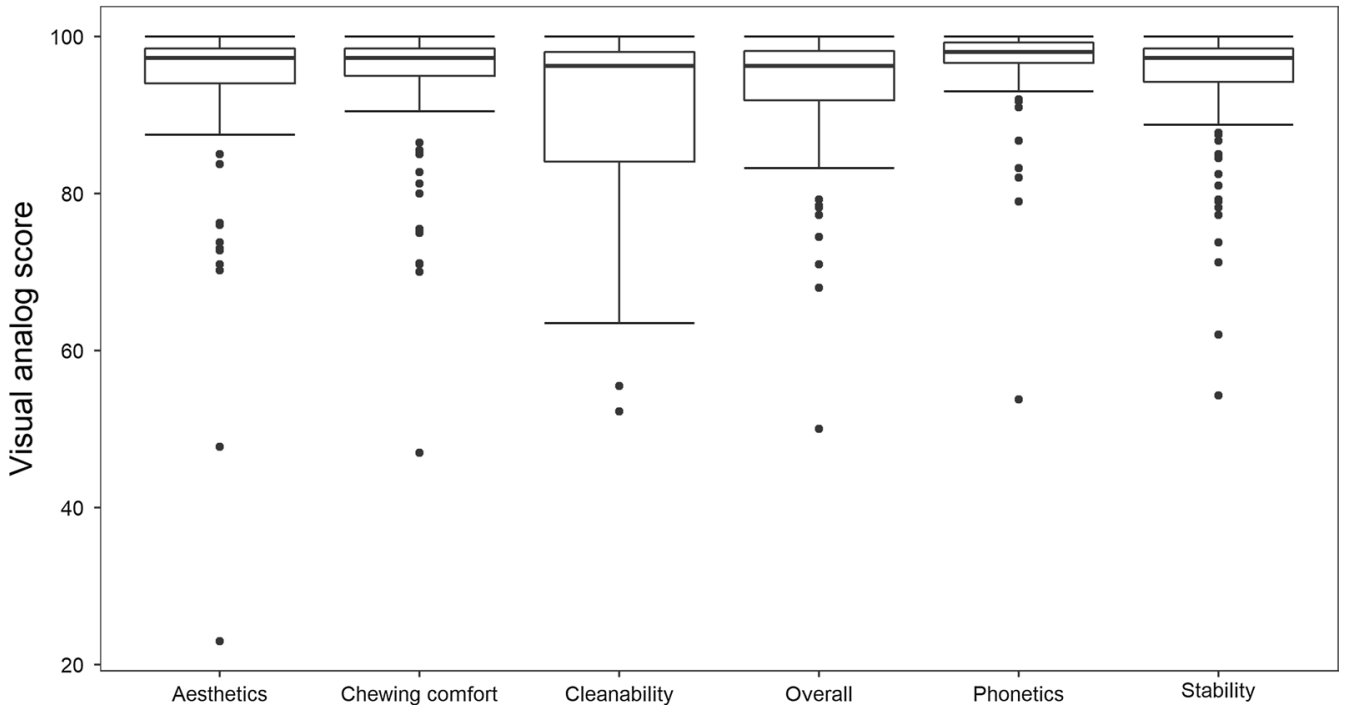

Fig. 2 Patient satisfaction. a Bar plot depict the relative frequency of the ordinal answers possibility of patient satisfaction answered by ordinal categories. $\mathbf{b}$ Box and whisker plots show the distribution of the VAS of the patient satisfaction

more that therapy with implant-supported restorations is a favorable treatment option for eligible patients.

The most common limitations were reported in the subgroups "functional limitations" and "physical pain". Almost half of all patients (48.4\%) complained about "food catching between teeth or underneath denture" (functional limitations) "occasionally", "often" or "very often". Prevalence between $15.0 \%$ and $25.0 \%$ was shown by impairments "bad breath" (functional limitations), "sensitive teeth" (physical pain), "sore spots" (physical pain) and "worried by problems" (psychological discomfort).

\section{Psychosocial impact of dental aesthetics questionnaire: PIDAQ}

The average PIDAQ score of all 95 patients was 20.5 ( $\mathrm{SD} \pm 11.3$, median 17.0, range $0-52$ ). One patient was perfectly satisfied with the aesthetics and showed a score 
Table 2 Summary of the answers from 91 evaluable OHIP questionnaires

\begin{tabular}{|c|c|c|c|c|c|}
\hline Prevalence of impairment in the past month & Never (\%) & Rarely (\%) & Occasionally (\%) & Often (\%) & Very often (\%) \\
\hline \multicolumn{6}{|l|}{ Functional limitation } \\
\hline Difficulty chewing & 67 & 24.2 & 8.8 & 0 & 0 \\
\hline Trouble pronouncing words & 94.5 & 3.3 & 2.2 & 0 & 0 \\
\hline Noticed tooth that doesn't look right & 89 & 3.3 & 6.6 & 1.1 & 0 \\
\hline Appearance affected & 83.5 & 13.2 & 2.2 & 1.1 & 0 \\
\hline Breath stale & 65.9 & 19.8 & 13.2 & 1.1 & 0 \\
\hline Taste worse & 90.1 & 9.9 & 0 & 0 & 0 \\
\hline Food catching & 28.6 & 23.1 & 30.8 & 12.1 & 5.5 \\
\hline Digestion worse & 87.9 & 9.9 & 2.2 & 0 & 0 \\
\hline Dentures not fitting & 98.9 & 0 & 1.1 & 0 & 0 \\
\hline \multicolumn{6}{|l|}{ Physical pain } \\
\hline Painful aching & 72.5 & 16.5 & 9.9 & 1.1 & 0 \\
\hline Sore jaw & 70.3 & 17.6 & 11 & 1.1 & 0 \\
\hline Headaches & 91.2 & 6.6 & 2.2 & 0 & 0 \\
\hline Sensitive teeth & 59.3 & 16.5 & 20.9 & 3.3 & 0 \\
\hline Toothache & 79.1 & 17.6 & 3.3 & 0 & 0 \\
\hline Painful gums & 63.7 & 27.5 & 8.8 & 0 & 0 \\
\hline Uncomfortable to eat & 85.7 & 6.6 & 5.5 & 2.2 & 0 \\
\hline Sore spots & 67 & 16.5 & 16.5 & 0 & 0 \\
\hline Uncomfortable dentures & 98.9 & 1.1 & 0 & 0 & 0 \\
\hline \multicolumn{6}{|l|}{ Psychological discomfort } \\
\hline Worried by dental problems & 68.1 & 13.2 & 15.4 & 2.2 & 1.1 \\
\hline Self-conscious & 84.6 & 12.1 & 2.2 & 1.1 & 0 \\
\hline Dental problems made you miserable & 86.8 & 13.2 & 0 & 0 & 0 \\
\hline Felt uncomfortable about the appearance & 84.6 & 11 & 4.4 & 0 & 0 \\
\hline Felt tense & 84.6 & 8.8 & 3.3 & 2.2 & 1.1 \\
\hline \multicolumn{6}{|l|}{ Physical disability } \\
\hline Speech unclear & 94.5 & 4.4 & 1.1 & 0 & 0 \\
\hline Others misunderstood & 91.2 & 8.8 & 0 & 0 & 0 \\
\hline Less flavor in food & 92.3 & 7.7 & 0 & 0 & 0 \\
\hline Unable to brush teeth & 79.1 & 14.3 & 6.6 & 0 & 0 \\
\hline Avoid eating & 90.1 & 5.5 & 2.2 & 2.2 & 0 \\
\hline Diet unsatisfactory & 91.2 & 7.7 & 1.1 & 0 & 0 \\
\hline Unable to eat (dentures) & 100 & 0 & 0 & 0 & 0 \\
\hline Avoid smiling & 87.9 & 9.9 & 2.2 & 0 & 0 \\
\hline Interrupt meals & 96.7 & 1.1 & 2.2 & 0 & 0 \\
\hline \multicolumn{6}{|l|}{ Psychological disability } \\
\hline Sleep interrupted & 87.9 & 7.7 & 4.4 & 0 & 0 \\
\hline Upset & 90.1 & 6.6 & 3.3 & 0 & 0 \\
\hline Difficult to relax & 63.7 & 27.5 & 8.8 & 0 & 0 \\
\hline Depressed & 87.9 & 8.8 & 3.3 & 0 & 0 \\
\hline Concentration affected & 87.9 & 11 & 1.1 & 0 & 0 \\
\hline Been embarrassed & 91.2 & 7.7 & 1.1 & 0 & 0 \\
\hline \multicolumn{6}{|l|}{ Social disability } \\
\hline Avoid going out & 97.8 & 2.2 & 0 & 0 & 0 \\
\hline Less tolerant of others & 84.6 & 14.3 & 1.1 & 0 & 0 \\
\hline Trouble getting on with others & 89 & 11 & 0 & 0 & 0 \\
\hline Irritable with others & 86.8 & 11 & 2.2 & 0 & 0 \\
\hline Difficulty doing jobs & 89 & 11 & 0 & 0 & 0 \\
\hline
\end{tabular}


Table 2 (continued)

\begin{tabular}{|c|c|c|c|c|c|}
\hline Prevalence of impairment in the past month & Never (\%) & Rarely (\%) & Occasionally (\%) & Often (\%) & Very often (\%) \\
\hline \multicolumn{6}{|l|}{ Handicap } \\
\hline Your general health has worsened & 85.7 & 9.9 & 4.4 & 0 & 0 \\
\hline Financial loss & 72.5 & 18.7 & 8.8 & 0 & 0 \\
\hline Unable to enjoy people's company & 89 & 8.8 & 0 & 1.1 & 1.1 \\
\hline Life unsatisfying & 76.9 & 19.8 & 3.3 & 0 & 0 \\
\hline Unable to function & 89 & 11 & 0 & 0 & 0 \\
\hline Unable to work & 91.2 & 8.8 & 0 & 0 & 0 \\
\hline
\end{tabular}

of 0 . The frequencies of the answer categories to all 23 questions are summarized in Table 3.

Dental self-confidence. Mean score was 13.9 ( $\mathrm{SD} \pm 5.2$, median 14.0, range 0-24). The statements of this subgroup, which describe a positive dental self-awareness, do not have many agreements as presented in Table 3.

Psychological impact. Mean score was 4.6 (SD \pm 4.4 , median 3.0, range $0-16$ ). In this subgroup impairments have a relatively high prevalence.

Social impact. Mean score was $1.8(\mathrm{SD} \pm 2.9$, median 0.0 , range $0-18$ ).

Table 3 Summary of distribution to answers to all 23 PIDAQ-Statements

\begin{tabular}{|c|c|c|c|c|c|}
\hline Statements & $\begin{array}{l}\text { Very stronly } \\
\text { (\%) }\end{array}$ & Strongly (\%) & Somewhat (\%) & A little (\%) & Not at all (\%) \\
\hline \multicolumn{6}{|l|}{ Dental self-confidence } \\
\hline Proud of own teeth & 5 & 14 & 30 & 17 & 33 \\
\hline Like to show own teeth & 6 & 31 & 28 & 16 & 18 \\
\hline Pleased to see own teeth in mirror & 7 & 21 & 33 & 26 & 13 \\
\hline Own teeth look attractive to others & 3 & 5 & 35 & 23 & 35 \\
\hline Satisfied with own teeth's appearance & 13 & 39 & 19 & 19 & 10 \\
\hline Find own teeth position nice & 8 & 23 & 30 & 19 & 21 \\
\hline \multicolumn{6}{|l|}{ Social impact } \\
\hline Hold back while smile & 0 & 1 & 6 & 9 & 84 \\
\hline Concerned what others think about my teeth & 0 & 1 & 6 & 7 & 85 \\
\hline afraid of offensive remarks from others & 0 & 1 & 1 & 3 & 95 \\
\hline Inhibited in social contacts because of own teeth & 1 & 0 & 0 & 8 & 91 \\
\hline Hiding own teeth with hand & 0 & 0 & 0 & 5 & 95 \\
\hline People stare at my teeth & 0 & 2 & 3 & 8 & 87 \\
\hline Irritated on remarks & 2 & 3 & 13 & 17 & 64 \\
\hline other gender find my teeth ugly & 0 & 0 & 4 & 7 & 89 \\
\hline \multicolumn{6}{|l|}{ Psychological impact } \\
\hline Envy others for their teeth & 5 & 13 & 21 & 19 & 41 \\
\hline Distressed because of others' nice teeth & 1 & 9 & 16 & 17 & 57 \\
\hline Unhappy about own teeth's appearance & 0 & 1 & 10 & 27 & 63 \\
\hline Think others have nicer teeth & 1 & 4 & 20 & 16 & 59 \\
\hline Feel bad about own teeth's appearance & 0 & 1 & 7 & 24 & 68 \\
\hline Wish own teeth to look better & 4 & 4 & 18 & 32 & 42 \\
\hline \multicolumn{6}{|l|}{ Aesthetic concern } \\
\hline Don't like own teeth in mirror & 0 & 3 & 12 & 26 & 59 \\
\hline Don't like own teeth on photos & 0 & 3 & 15 & 16 & 65 \\
\hline Don't like own teeth on video & 1 & 2 & 8 & 24 & 65 \\
\hline
\end{tabular}


Aesthetic concern. Mean score was 1.7 ( $\mathrm{SD} \pm 1.9$, median 1.0 , range $0-7$ ). This indicates that patients were less affected from social impact and aesthetic concern. Most negative statements in these two subgroups did not find more than 5\% consents for "strongly" or "very strongly" (Fig. 3).

\section{Influencing factors on PROMs}

Patient satisfaction. A slight tendency that presence of a moderate/severe peri-implantitis had an impact on satisfaction could be detected (Table 4). Patients with moderate/severe peri-implantitis showed a lower overall satisfaction compared to patients with no peri-implantitis on the ordinal scale (ordinal: $p=0.012$, VAS: $p=0.026$ ). A higher odds ratio refers to a higher ordinal score that corresponds to a lower satisfaction whereas a lower VAS refers to a lower satisfaction. For the items "less stability" and "less satisfaction with aesthetics" this tendency is also seen for both the ordinal scale and VAS $(p<0.001$, VAS: $p=0.010 ; p=0.050$, VAS: $p=0.009$; respectively). For the small subgroup of patients with removable prostheses, a statistical significant effect was also observed for the item 'less stability' on the ordinal scale $(p=0.034)$. Younger patients showed rather 'less satisfaction with aesthetics' on the VAS ( $p=0.037)$. Regarding the item 'phonetic' patients with implants in the frontal region were less satisfied on VAS $(p=0.017)$.

Two models, i.e. the model for "Treatment would be chosen again" and ordinal "Phonetics", could not be conducted because of the too negligible differences between patient choices.

OHIP and PIDAQ. Statistical analysis showed no statistically significant impact on OHIP. On PIDAQ the factor removable prostheses had an impact $(p=0.007)$.

\section{Discussion}

At the VIII. European Workshop on Periodontology Tonetti and Palmer [5] proposed that clinical research in implant dentistry should not only assess biological complications (like implant loss, peri-implant mucositis or peri-implantitis) and technical complications, but also focus on patient's satisfaction and aesthetic outcomes. Therefore, next to biological and technical complications contained in a previous paper (Bäumer et al. [29]), longterm study data on patient satisfaction with implant-supported restorations 10 years after implant placement are presented.

\section{Patient satisfaction}

Overall, the patient survey shows a very high degree of satisfaction with implant-supported restorations, both functionally and aesthetically. All patients were highly satisfied with their phonetics and most with their chewing comfort, cleanability and stability of the restoration. Except for one patient, all were very or mostly satisfied with the aesthetics and would choose this treatment again. These results are comparable with a cohort study from Switzerland [32] with 104 patients recruited 5-15 years (mean: 10.2 years) after implantation for follow-up examination. In both studies, over $90 \%$ of patients

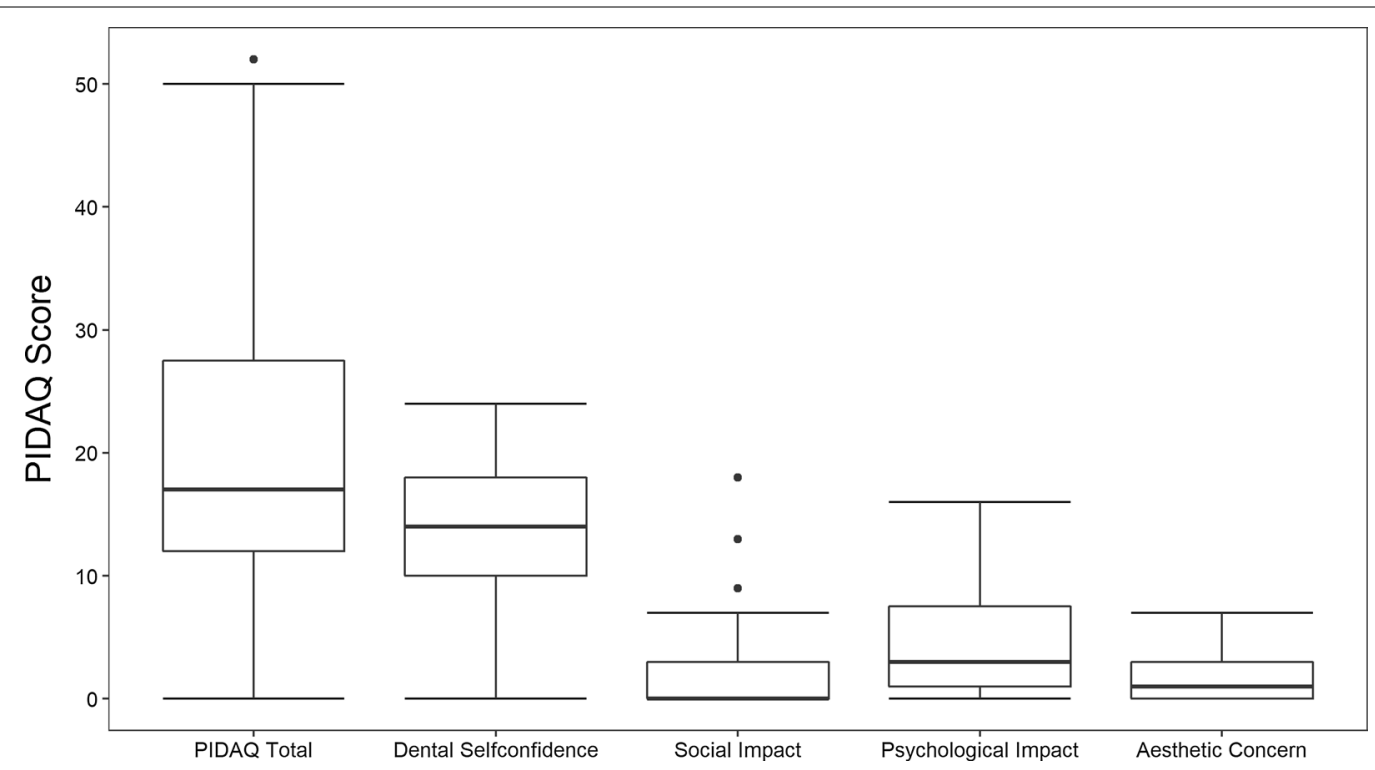

Fig. 3 PIDAQ. Box and whisker plots show the distribution of the PIDAQ score and its subgroups 


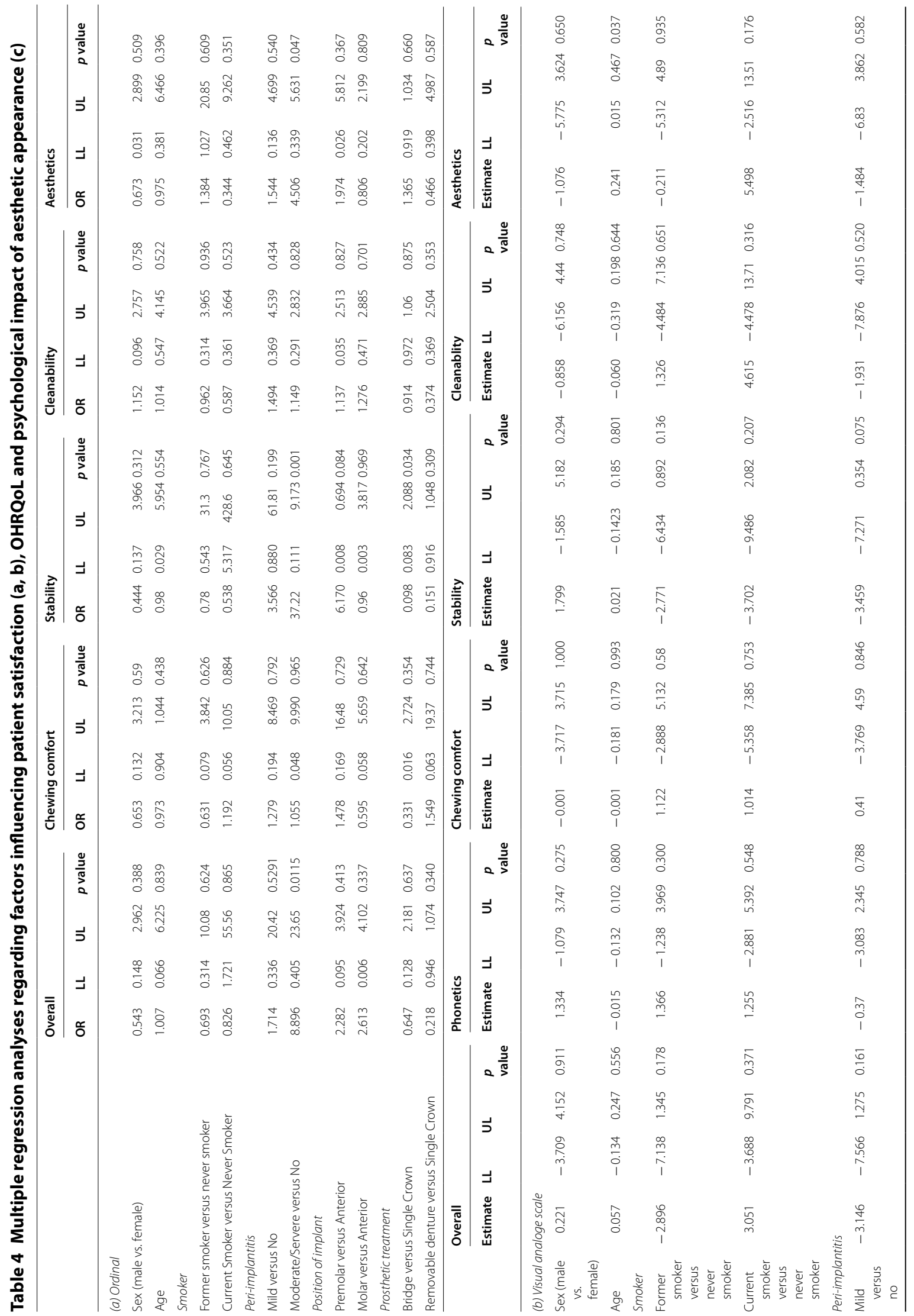




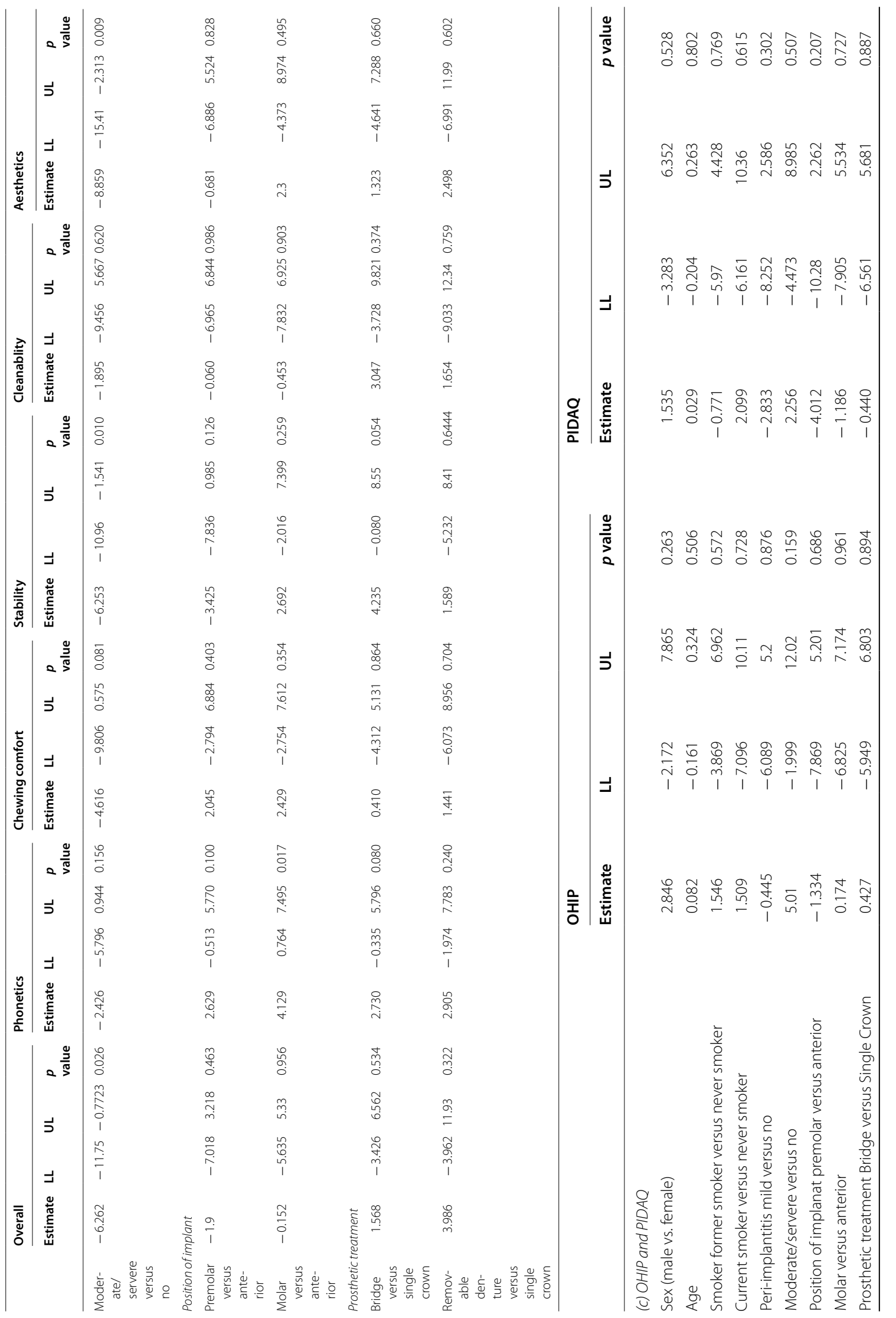




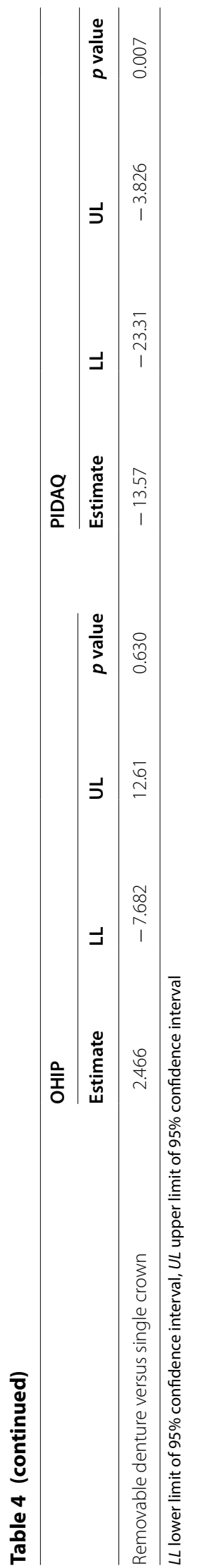


are fully satisfied with implant-supported restorations. This is also in accordance with another retrospective study from France, which reported on satisfaction 10-16 years after implantation [24]. Sligthly lower subjective satisfaction of patients were found in a retrospective study from Germany with 37 hypodontia patients recruited 0.5-16 years after implantation, however the results were then improved by using objective assessments [33]. Despite of the small sample size of patients with implant-supported removable prostheses in our study (only five patients), a great OHRQoL among the patients with implant-supported removable prostheses could also be confirmed, even though none of the removable prostheses were free from clinical complications and require more prosthetic maintenance [34].

In OHIP some impairments could be found in this patient group. For example, half of the patients complained about food impaction between their teeth/ implants. Additionally, to the fact that interdental spaces between implants and teeth-especially in the molar regions-are wider than in natural dentitions, most of the patients were periodontally compromised, which include wider interdental spaces with increased food catching problems also between teeth. Further impairments such as sensitive teeth are also caused by recessions in periodontally compromised situations and do not have an association with the conducted implant therapy.

The similarity of the results regarding patient-reported quality of life (OHIP) in this study with the result found for the population with natural teeth without dentures from the German cross-sectional study also reflects the positive effect of implant-supported restorations for patients [17]. Based on frequency distribution of the OHIP scores, the patient population presented here compares better to the group with natural teeth (without removable dentures) than to the group with natural teeth and removable dentures. The average age of the patients in this study is higher than the patient group studied by John et al. [17]. Also, the education level of the patients is higher in comparison. Only $8.1 \%$ of all subjects in the German cross-section study obtained a college or university degree, whereas more than $57 \%$ of patients in this study graduated from college or university. The gender distribution was slightly different $(60 \%$ women in our study, $52 \%$ women by John et al.).

Thus, it can be assumed that by means of fixed implantsupported restorations, patients are almost as satisfied as the population with natural teeth regarding function and aesthetics. This is in agreement with two other studies using OHIP-G14, a short-form of OHIP in German with only 14 questions. They report an improved quality of life for patients that received therapies with implant-supported restorations. One of the studies started out from a periodontally compromised situation [16]. The other one surveyed the identical implant system (XiVE), but with an observation period of 7.5 years [28]. Compared to the OHIP-Scores $(32.6 \pm 30.1)$ reported in a 10 -year followup study in the Netherlands on 28 oligodontia patients rehabilitated with implant-based fixed prosthodontics [35], the results of the present study $(10.8 \pm 10.8)$ appear more homogenous and patients reported higher satisfaction. Aesthetic satisfaction seems to be more challenging with oligodontia patients, since bone augmentation is almost mandatory due to the lack of native bone, both in vertical and horizontal dimension. Nevertheless, both studies suggested implant treatment to be a predictable and satisfactory treatment modality for missing teeth.

PIDAQ shows implant-supported restorations positively affect not only oral and dental health, but also the dental aesthetics-related quality of life. Only "dental selfconfidence" showed reduced results, and reflects the selfcritical attitude of the patient population. Developed for the assessment of psychosocial impact of dental aesthetics after orthodontic treatments, this questionnaire could only be found once in the literature relating to implantation: gender and educational differences were suggested to exist [21]. Gender influence has not been confirmed in the present study, but a direct comparison between these two studies is difficult, since Chen et al. [21] weighted the single questions additionally.

All together, this indicates again that therapy with implant-supported restorations is a favorable treatment option for eligible patients.

\section{Limitations}

The cross-sectional nature of data collection in this study as well as the absence of baseline data to assess changes due to the treatment 'implant placement' is a major limitation in this study. The patient expectation at baseline regarding the therapeutic outcome, which may also influence satisfaction [36], is not available. To overcome these limitations and also to avoid a possible 'recall bias' i.e. to recruit more satisfied than dissatisfied patients, since dissatisfied patients might seek further treatment somewhere else [37], prospective studies are required in the future.

Also, the examined patients did not represent an average population. All patients were highly educated, showed a high average age $(63.4 \pm 10.4$ years $)$ and most patients were restored with fixed-implant supported restorations.

Furthermore, the analysis regarding influencing factors on patient's satisfaction has to be interpreted with care. On the one hand, there might be relevant factors, that were excluded in multiple regression analyses, and other not relevant factors were included. On the other hand, 
included factors were biased due to study design. So, in case of the factor peri-implanitits in this study it has to be borne in mind that patients were informed on their periimplantitis before they completed the questionnaires. Accordingly, an association should be assumed.

\section{Conclusions}

Patients treated with XIVE and Frialite implants showed a high patient's satisfaction 10 years after implant placement. The factors moderate/severe peri-implantitis, age, implant position and type of restoration were identified as potentially influencing patient's satisfaction, but these results have to be interpreted with care due to the crosssectional design.

\section{Supplementary Information}

The online version contains supplementary material available at https://doi. org/10.1186/s12903-020-01381-3.

Additional file 1. Patients satisfaction: Comparison of answers regarding $\mathrm{PROM}$ given on questionnaire and VAS.

\section{Abbreviations}

AG: Aggressive periodontitis; APT: Active periodontal therapy; Cl: Confidence interval; CP: Chronic periodontitis; Fa.: Firm; OHIP: Oral health impact profile; OHRQOL: Oral health-related quality of life; PIDAQ: Psychosocial impact of dental aesthetics questionnaire; PROM: Patient-reported Outcome Measures; SD: Standard deviation; VAS: Visual analog scale.

\section{Acknowledgements}

We would like to gratefully acknowledge the statistical consultation of Dr. Christian Kuffer.

\section{Authors' contributions}

GK inserted all implants. AB examined all included patients retrospectively. YW and DB entered all data on the basis of the file search. AKO analyzed and interpreted the data (statistician). $A B$ and $Y W$ were major contributors in writing the manuscript. All authors read and approved the final manuscript.

\section{Funding}

The work was supported by Fa. Dentsply Sirona Implants (Mannheim, Germany) (Grant No. DF-05-13-1-321-1-2). It was self-funded by the authors and their institutions in its major parts.

\section{Availability of data and materials}

The datasets used and analysed during the current study are available from the corresponding author on reasonable request.

\section{Ethics approval and consent to participate}

The study was performed in accordance with the Declaration of Helsinki 1975, as revised in 2008, and was approved by the Institutional Review Board for Human Studies of the Medical Faculty of Heidelberg University (Application\# S-210/2013). All patients were informed about possible risks and benefits as well as the procedures of the study and all gave written informed consent.

\section{Consent for publication}

Not applicable.

\section{Competing interests}

Author A. Bäumer declares that she has received research grants from Company Dentsply Sirona Implant, Hain Life Sciene and speaker honorarium from the following Companies: American Dental Systems, Dentsply Sirona Implant and Tecnoss. Author G. Körner has received speaker honorarium from the following Companies: American Dental Systems, Geistlich, Dentsply Sirona Implant, Tecnoss, Nobel Biocare, Quintessence, Camlog, 3i, Gebrüder Martin, BEGO. The authors Y. Wang, D. Bäumer and A.-K. Ozga declare that they have no conflict of interest.

\section{Author details}

${ }^{1}$ Private Practice, Munich, Germany. ${ }^{2}$ Institute of Medical Biometry and Epidemiology, University Medical Center Hamburg-Eppendorf, 20246 Hamburg, Germany. ${ }^{3}$ Institute of Medical Biometry and Informatics, University of Heidelberg, 69120 Heidelberg, Germany. ${ }^{4}$ Private Practice, Niedernstrasse 16, 33602 Bielefeld, Germany. ${ }^{5}$ Section of Periodontology, Department of Conservative Dentistry, Clinic for Oral, Dental and Maxillofacial Diseases, University Hospital Heidelberg, Im Neuenheimer Feld 400, 69120 Heidelberg, Germany.

Received: 1 May 2020 Accepted: 22 December 2020

Published online: 14 January 2021

\section{References}

1. Brocard D, Barthet P, Baysse E, Duffort JF, Eller P, Justumus P, Marin P, Oscaby F, Simonet T, Benque $E$, et al. A multicenter report on 1022 consecutively placed ITI implants: a 7-year longitudinal study. Int J Oral Maxillofac Implants. 2000;15(5):691-700.

2. Buch RS, Weibrich G, Wagner W. Criteria of success in implantology. Mund-, Kiefer- und Gesichtschirurgie : MKG. 2003;7(1):42-6.

3. Allen PF. Assessment of oral health related quality of life. Health Qual Life Outcomes. 2003;1:40.

4. McGrath C, Lam O, Lang N. An evidence-based review of patientreported outcome measures in dental implant research among dentate subjects. J Clin Periodontol. 2012;39(Suppl 12):193-201.

5. Tonetti M, Palmer R. Clinical research in implant dentistry: study design, reporting and outcome measurements: consensus report of Working Group 2 of the VIII European Workshop on Periodontology. J Clin Periodontol. 2012:39(Suppl 12):73-80.

6. Gerritsen AE, Allen PF, Witter DJ, Bronkhorst EM, Creugers NH. Tooth loss and oral health-related quality of life: a systematic review and metaanalysis. Health Qual Life Outcomes. 2010;8:126.

7. Buch RS, Weibrich G, Wegener J, Wagner W. Patient satisfaction with dental implants. Mund-, Kiefer- und Gesichtschirurgie. 2002;6(6):433-6.

8. Lang NP, Zitzmann NU. Clinical research in implant dentistry: evaluation of implant-supported restorations, aesthetic and patient-reported outcomes. J Clin Periodontol. 2012;39(Suppl 12):133-8.

9. Allen PF, McMillan AS, Locker D. An assessment of sensitivity to change of the Oral Health Impact Profile in a clinical trial. Commun Dent Oral Epidemiol. 2001;29(3):175-82.

10. Murray H, Locker D, Mock D, Tenenbaum HC. Pain and the quality of life in patients referred to a craniofacial pain unit. J Orofac Pain. 1996;10(4):316-23.

11. Slade GD. Assessing change in quality of life using the oral health impact profile. Commun Dent Oral Epidemiol. 1998;26(1):52-61.

12. Slade GD, Spencer AJ. Social impact of oral conditions among older adults. Aust Dent J. 1994;39(6):358-64.

13. Slade GD, Spencer AJ. Development and evaluation of the oral health impact profile. Commun Dent Health. 1994;11(1):3-11.

14. Slade GD, Strauss RP, Atchison KA, Kressin NR, Locker D, Reisine ST. Conference summary: assessing oral health outcomes-measuring health status and quality of life. Commun Dent Health. 1998;15(1):3-7.

15. John MT, Patrick DL, Slade GD. The German version of the oral health impact profile-translation and psychometric properties. Eur J Oral Sci. 2002;110(6):425-33.

16. Fischer KR, Lindner I, FickI S. Implant treatment in periodontally compromised subjects - quality of life and patient satisfaction. Clin Oral Invest. 2016;20(4):697-702

17. John MT, LeResche L, Koepsell TD, Hujoel P, Miglioretti DL, Micheelis W. Oral health-related quality of life in Germany. Eur J Oral Sci. 2003;111(6):483-91.

18. Nickenig HJ, Wichmann M, Terheyden H, Kreppel M. Oral health-related quality of life and implant therapy: a prospective multicenter study of preoperative, intermediate, and posttreatment assessment. J CranioMaxillo-Facial Surg. 2016;44(6):753-7. 
19. Klages U, Claus N, Wehrbein H, Zentner A. Development of a questionnaire for assessment of the psychosocial impact of dental aesthetics in young adults. Eur J Orthod. 2006;28(2):103-11.

20. Bucci R, Rongo R, Zito E, Galeotti A, Valletta R, D'Anto V. Cross-cultural adaptation and validation of the Italian Psychosocial Impact of Dental Aesthetics Questionnaire (PIDAQ). Qual Life Res. 2015;24(3):747-52.

21. Chen P, Yu S, Zhu G. The psychosocial impacts of implantation on the dental aesthetics of missing anterior teeth patients. Br Dent J. 2012;213(11):E20.

22. Klages U, Erbe C, Sandru SD, Brullman D, Wehrbein H. Psychosocial impact of dental aesthetics in adolescence: validity and reliability of a questionnaire across age-groups. Qual Life Res. 2015;24(2):379-90.

23. Twigge E, Roberts RM, Jamieson L, Dreyer CW, Sampson WJ. The psychosocial impact of malocclusions and treatment expectations of adolescent orthodontic patients. Eur J Orthod. 2016;38(6):593-601.

24. Simonis $P$, Dufour T, Tenenbaum $H$. Long-term implant survival and success: a 10-16-year follow-up of non-submerged dental implants. Clin Oral Implant Res. 2010;21(7):772-7.

25. Derks J, Tomasi C. Peri-implant health and disease. A systematic review of current epidemiology. J Clin Periodontol. 2015:42(Suppl 16):S158-171.

26. Mertens C, Steveling HG, Stucke K, Pretzl B, Meyer-Baumer A. Fixed implant-retained rehabilitation of the edentulous maxilla: 11-year results of a prospective study. Clin Implant Dentistry Related Res. 2012;14(6):816-27.

27. Roccuzzo M, Bonino L, Dalmasso P, Aglietta M. Long-term results of a three arms prospective cohort study on implants in periodontally compromised patients: 10-year data around sandblasted and acid-etched (SLA) surface. Clin Oral Implant Res. 2014;25(10):1105-12.

28. Gjelvold B, Chrcanovic BR, Bagewitz IC, Kisch J, Albrektsson T, Wennerberg $A$ : Esthetic and patient-centered outcomes of single implants: a retrospective study. Int J Oral Maxillofac Implants 2017.
29. Bäumer A, Toekan S, Saure D, Körner G. Survival and success of implants in a private periodontal practice: a 10 year retrospective study. BMC Oral Health. 2020;20(1):92.

30. Huskisson EC. Measurement of pain. Lancet (London). 1974;2(7889):1127-31.

31. Allen PF, Locker D. Do item weights matter? An assessment using the oral health impact profile. Commun Dent Health. 1997:14(3):133-8.

32. Pjetursson BE, Karoussis I, Burgin W, Bragger U, Lang NP. Patients' satisfaction following implant therapy. A 10-year prospective cohort study. Clin Oral Implants Res. 2005;16(2):185-93.

33. Attia S, Schaaf H, El Khassawna T, Malhan D, Mausbach K, Howaldt HP, Streckbein P. Oral rehabilitation of hypodontia patients using an endosseous dental implant: functional and aesthetic results. J Clin Med. 2019;8:10.

34. Schuster AJ, Possebon A, Marcello-Machado RM, Chagas-Júnior OL, Faot F. Masticatory function and oral health-related quality of life of patients with atrophic and non-atrophic mandibles using implant-retained mandibular overdentures: 3-year results of a prospective clinical study. J Oral Rehabil. 2020;1:1.

35. Filius MAP, Vissink A, Cune MS, Raghoebar GM, Visser A. Long-term implant performance and patients' satisfaction in oligodontia. J Dent. 2018;71:18-24.

36. Yao J, Tang H, Gao XL, McGrath C, Mattheos N. Patients' expectations to dental implant: a systematic review of the literature. Health Qual Life Outcomes. 2014:12:153.

37. Locker D. Patient-based assessment of the outcomes of implant therapy: a review of the literature. Int J Prosthodont. 1998;11(5):453-61.

\section{Publisher's Note}

Springer Nature remains neutral with regard to jurisdictional claims in published maps and institutional affiliations.
Ready to submit your research? Choose BMC and benefit from:

- fast, convenient online submission

- thorough peer review by experienced researchers in your field

- rapid publication on acceptance

- support for research data, including large and complex data types

- gold Open Access which fosters wider collaboration and increased citations

- maximum visibility for your research: over $100 \mathrm{M}$ website views per year

At BMC, research is always in progress.

Learn more biomedcentral.com/submissions 